\title{
De Raynal a De Pradt: apontamentos para um estudo da idéia de emancipação da América e sua leitura no Brasil'
}

From Raynal to De Pradt: Notes for a Study of the Idea of Emancipation of America and its presence in Brazil

\author{
João Paulo Garrido Pimenta \\ Professor no Departamento de \\ História da Universidade de São \\ Paulo (FFLCH / USP - São Paulo / \\ Brasil) \\ e-mail: jgarrido@usp.br
}

\begin{abstract}
Resumo
Este artigo oferece uma análise da integração, no bojo do processo que resultou na independência do Brasil, entre exemplos históricos concretos de ruptura entre colônias e metrópoles, e enunciados de caráter doutrinário e programático em torno da mesma questão que, presentes no universo luso-americano, ofereciam, aos homens da época, parâmetros de ação política. Destacam-se escritos produzidos sobre a América espanhola, publicados e consumidos no mundo luso-americano. Escritos como os de Raynal e De Pradt que, de alguma maneira, balizaram visões de mundo e comportamentos coletivos em mutação, contribuindo para a criação, nas primeiras décadas do século XIX, de um ambiente intelectual onde a ruptura entre a metrópole portuguesa e suas colônias americanas pôde não apenas ser concebida, mas efetivamente realizada.
\end{abstract}

\begin{abstract}
This article proposes an analysis, from within the process which led to the independence of Brazil, of the confluence between concrete historical examples of rupture between colonies and metropolis, and the statements of doctrinarian and programmatic nature around the same question; which, by being present in the Luso-American region, offered references for political action. The analysis particularly focuses on the writings regarding Spanish America published and read in the Luso-American world. In a certain way, those writings seem to have affected the visions of the world and to have shaped collective behaviours. This contributed to create an intellectual environment in the first decades of the 19th century, where the rupture between the Portuguese metropolis and its American colonies was not just conceived, but carried out.
\end{abstract}

\section{Palavras-chave}

América portuguesa / Brasil, América espanhola, Independência, história das idéias, imprensa, lluminismo

\section{Keywords}

Portuguese America / Brazil, Spanish America, Independence, history of ideas, press, Enlightenment 
RAYNAL, Guillaume-Thomas François. A revolução na América. Rio de Janeiro: Arquivo Nacional, 1993, p.131. No Brasil, a publicação apenas parcial da Histoire philosophique é acrescida de: Idem. 0 estabelecimento dos portugueses no Brasil. Rio de Janeiro/Brasília: Arquivo Nacional/Ed.Unb, 1998.

3

VENTURA, Roberto. Leituras do abade Raynal na América Latina. In: COGGIOLA, 0. (org.). A Revolução Francesa e seu impacto na América Latina. São Paulo: Nova Stela, 1990. p.165-179; VILLALTA, Luiz. 0 que se fala e o que se lê: língua, instrução e leitura. In: SOUZA, Laura de M. e (org.). História da vida privada no Brasil. Vol.1: cotidiano e vida privada na América portuguesa. São Paulo: Companhia das Letras, 1997. p.331-385; ARAÚJ0, Ana Cristina. Um império, um reino e uma monarquia na América: as vésperas da independência do Brasil. In: JANCSÓ, István (org.). Independência: história e historiografia. São Paulo: Hucitec, 2005. p.235-270.

A bibliografia a respeito é ampla e variada. Algumas das obras mais importantes são: MOTA, Carlos G. Atitudes de inovação no Brasil. Lisboa: Horizonte, s.d.; MAXWELL, Kenneth. A devassa da devassa. A Inconfidência Mineira. 2a.ed. Rio de Janeiro: Paz \&t Terra, 1978; SANTOS, Afonso M. dos. No rascunho da nação. Inconfidência no Rio de Janeiro. Rio de Janeiro: Secretaria Municipal de Cultura, Turismo e Esportes, 1992; e JANCSÓ, István. Na Bahia, contra o Império. História do ensaio de sedição de 1798. São Paulo/Salvador: Hucitec/EDUFBA, 1995. Em várias bibliotecas de implicados em tais movimentos de contestação, a obra de Raynal era freqüente.

5

KOSELLECK, Reinhardt. Critica e crise. Uma contribuição à patogênese do mundo burguês. Rio de Janeiro: EDUERJ/Contraponto, 1999. p.152. Em sua definição, "pertence à natureza da crise que uma decisão esteja pendente mas ainda não tenha sido tomada. Também reside em sua natureza que a decisão a ser tomada permaneça em aberto. Portanto, a insegurança geral de uma situação crítica é atravessada pela certeza de que, sem que se saiba ao certo quando ou como, o fim do estado crítico se aproxima. A solução possivel permanece incerta, mas o próprio fim, a transformação das circunstâncias vigentes - ameaçadora, temida ou desejada -, é certo. A crise invoca a pergunta ao futuro histórico" (Idem, p.111).

6

Referência clássica é a obra de GERBI, Antonello. La disputa del Nuevo Mundo. Historia de una polémica 1750-1900. 2.ed. México: FCE, 1993. Sobre o desenvolvimento dos prognósticos políticos e sua relação com o advento da modernidade, a obra fundamental é a de KOSELLECK. Op.Cit. 0 trabalho cujos objetivos mais se aproximam dos meus é o de MOREL, Marco. Independência no papel: a imprensa periódica. In: JANCSÓ, István (org.). Op.Cit. p.617-636.

No emaranhado de paradigmas positivos ou negativos, alternativas, possibilidades e parâmetros de ação fornecidos pela experiência revolucionária moderna aos homens envolvidos na politica lusoamericana, aquilo que chamo de "experiência hispano-americana" possui uma grande singularidade:
Quando em 1770 teve início, em Amsterdã, a publicação da obra de Guillaume-Thomas François Raynal, Histoire philosophique et politique des établissements et du commerce des européens dans les deux Indes. os espaços públicos de discussão política do mundo ocidental puderam dispor de um notável arcabouço de reflexões que, ao mesmo tempo em que renovariam o movimento de ampliação acelerada desses espaços, dotarIhes-ia de novos pretextos e conteúdos. Seis anos depois, quando as Treze Colônias inglesas da América do Norte declararam sua independência, a obra de Raynal já era um verdadeiro best-seller, sendo reescrita à medida que o mundo que cercava seu autor oferecia oportunidades de confirmação ou revisão de seus prognósticos. Dentre eles, o de que "o novo hemisfério [a América] deve, um dia, desligar-se do velho".2

Na América portuguesa, a obra de Raynal aportou junto com o ineditismo de uma experiência histórica que mostrava, pela primeira vez desde o início dos estabelecimentos europeus no Novo Mundo, um exemplo concreto de ruptura política entre colônias e metrópoles. ${ }^{3} \mathrm{~A}$ independência das Treze Colônias e a Histoire de Raynal integrar-se-iam no imaginário político luso-americano, logo adensado também com os acontecimentos da França, a partir de 1789, e de Saint-Domingue, a partir de 1791. Nenhum desses movimentos precipitaria, de imediato, a eclosão de outros, de natureza semelhante, no mundo colonial português; no entanto, manifestações de descontentamento com a gestão política metropolitana iam se tornando mais agudas, com seus implicados revelando conhecimento do que se passava mundo afora e mobilizando a atenção dos estadistas lusos empenhados na reforma de um estado de coisas que, reconhecidamente, se encontrava em desarranjo:4 o que configurava um dos muitos quadrantes de uma crise geral que englobava todo o mundo ocidental, e da qual Raynal era - nas palavras de Koselleck - um "autêntico profeta". 5

Do lado português, tal crise encontraria seu auge no colapso metropolitano de 1807, num momento de brutal aceleração de um processo de acúmulo de experiências históricas que, doravante, enquadraria a trajetória política das relações entre Portugal e seus domínios americanos, contribuindo de maneira decisiva para a definição, quinze anos depois, da independência do Brasil. Um processo em meio ao qual os Estados Unidos da América, a França e o Haiti continuariam a ser elementos vivos, mas agora ombreados pela convulsionada América espanhola, perante a qual um grande número de autores continuaria a prognosticar, como fizera Raynal, a independência de todo o continente.

As páginas seguintes oferecem uma análise da integração, no bojo do processo que resultou na independência do Brasil, de exemplos históricos concretos de ruptura entre colônias e metrópoles, com enunciados de caráter doutrinário e programático em torno da mesma questão que, presentes no universo luso-americano, ofereciam, aos homens da época, parâmetros de ação política. Não pretendo tratar, à exaustão, dos exemplos e doutrinas que desde meados do século XVIII se faziam cada vez mais presentes no mundo ocidental, dos quais um número significativo dizia respeito à situação da América de colonização ibérica e prognosticava sua independência. ${ }^{6}$ Minha proposta é mais específica: deter-me-ei àquilo que, em outra ocasião, denominei "a experiência hispano-americana",7 
além de ser gestada a partir de uma releitura histórica dos acontecimentos (isto é, experiência como sinônimo de conhecimento de uma realidade), a dissolução da ordem monárquica na América espanhola é "experimentada" no mundo luso-americano igualmente como interface com aqueles acontecimentos (isto é, experiência como sinônimo de vivência de uma realidade). Uma sintese de meu argumento encontra-se em PIMENTA, João Paulo G. Brasil y las independencias de Hispanoamérica. Castelló de la Plana: Publicacions de la Universitat Jaume I, 2007, cap.I.

ARTOLA, Miguel. La burguesia revolucionaria (1808-1874). Madrid: Alianza, 1990; GUERRA, François-Xavier. Modernidad e independencias. Ensayos sobre las revoluciones hispánicas. 2a.ed. México: FCE, 1993; ALEXANDRE, Valentim. Os sentidos do império: questão nacional e questão colonial na crise do Antigo Regime português. Porto: Afrontamento, 1993.

VILLALTA, Luiz. 0 que se fala e o que se lê: língua, instrução e leitura. In: SOUZA, Laura de M. e (org.). História da vida privada no Brasil. Vol.1: cotidiano e vida privada na América portuguesa. São Paulo: Companhia das Letras, 1997 JANCSÓ, István. A sedução da liberdade: cotidiano e contestação politica no final do século XVIII. In: SOUZA, Laura de M. e (org.). Op.Cit.; MOREL, Marco. As transformações dos espaços públicos. Imprensa, atores politicos e sociabilidades na cidade imperial (1820-1840). São Paulo: Hucitec, 2005; NEVES, Lúcia. Corcundas e constitucionais: a cultura política da independência. Rio de Janeiro: Revan/Faperj, 2003; SLEMIAN, Andréa. Vida política em tempo de crise: Rio de Janeiro, 1808-1824. São Paulo: Hucitec, 2006. Sobre Portugal: TENGARRINHA, José. Da liberdade mitificada à liberdade subvertida: uma exploração no interior da repressão à imprensa periódica de 1820 a 1828. Lisboa: Colibri, 1993; sobre Espanha e América espanhola, valiosas contribuições em GUERRA, François-Xavier; LEMPÉRIĖRE, Annick (et.al.). Los espacios públicos en Iberoamérica: ambiguedades y problemas. Siglos XVIII-XIX. México: FCE, 1998. destacando escritos produzidos sobre o processo de independência da América espanhola, publicados e consumidos no mundo luso-americano. Escritos que, de alguma maneira, pareceram balizar visões de mundo e comportamentos coletivos em mutação, contribuindo para a criação, nas primeiras décadas do século XIX, de um ambiente intelectual onde a ruptura entre a metrópole portuguesa e suas colônias americanas pôde não apenas ser concebida, mas efetivamente realizada.

A fonte comum do colapso das monarquias ibéricas entre 1807 e 1808 criou uma situação aparentemente dispar: enquanto a acefalia da monarquia espanhola conduzia à fragmentação da unidade imperial bourbônica, a transferência da Corte portuguesa para o Brasil obedecia a uma estratégia de manutenção da unidade imperial bragantina, sobretudo de preservação de suas extensas e ricas possessões americanas. ${ }^{8}$ No entanto, o imediatismo de tal disparidade não se sobrepunha à profunda articulação que colocava Espanha e Portugal lado-a-lado numa mesma crise que, em termos práticos, implicava a mais séria ameaça jamais enfrentada à existência politica dos dois impérios. Publicamente reconhecida pelas suas respectivas instâncias representativas, a gravidade de tal situação impunha pronta mobilização.

Do lado português, a instalação do governo do príncipe D. João no Rio de Janeiro em 1808 implicou o desenvolvimento de uma política voltada com especial interesse para o continente americano. Com ela, a Corte do Brasil buscava, no plano externo, um difícil equilíbrio entre agressividade e circunspeção, trocando agentes diplomáticos com os diversos governos dos vice-reinos hispânicos - alguns dos quais rivais entre si -, tramando projetos de extensão a eles de sua influência, fortalecendo a vigilância sobre suas fronteiras e acenando com a possibilidade de cruzá-las e promover invasões militares dos territórios contíguos ao Brasil. Nos anos seguintes, com os processos independentistas na América espanhola e as subseqüentes guerras civis, a restauração européia, as duas invasões portuguesas da Província Oriental e o aprofundamento das tensões e fissuras internas no mundo português, a situação se tornaria ainda mais complexa, numa sobreposição de duas trajetórias que, se em 1808 pareciam diametralmente opostas, conduziram, entre 1821 e 1822, à independência tanto da maior parte da América espanhola quanto do Brasil.

Um dos fatores que explicam esse ponto de chegada é a sustentação da vida política portuguesa entre os anos de 1808 e 1822 em espaços públicos de discussão cada vez mais largos e densos, ${ }_{1}^{9}$ nos quais o acompanhamento constante e detalhado do que ocorria na América espanhola representava uma questão de sobrevivência em meio a um panorama de incertezas e temores que demandava exemplos, paradigmas e parâmetros de ação. Dentre estes, os tradicionalmente oferecidos pelos Estados Unidos, França e Haiti se mantinham vivos, mas perdiam terreno para outros, dotados de maior vitalidade, advindos da América espanhola. A trajetória desta não apenas advertia, reiteradamente, que a América portuguesa poderia seguir um caminho daquilo que à época podia ser concebido como "fragmentação", 
10

Correio Braziliense ou Armazém Literário. Londres: 1808-1822, 29 vols. (edição facsimilar: São Paulo/ Brasilia: Imprensa Oficial/Correio Brasiliense, 2003, 31 vols.).

11

Resenhada pela Edinburgh Review n.XXII, sendo esta analisada pelo Correio Brasiliense v.II, n.11, 04/1809; n.12, 05/1809; e n.13, 06/1809.

12

Resenhada pela Edinburgh Review n.XXIII, sendo esta analisada pelo Correio Brasiliense v.III, n.16, 09/1809.

13

Resenhado pela Edinburgh Review no n.XXXI, sendo esta analisada pelo Correio Brasiliense v.IV, n.25, 06/1810. "anarquia" e "destruição", como também encorajava a alternativa de ruptura com a metrópole européia. Uma alternativa que a América espanhola, por meio de uma pequena e precoce diferença temporal, em termos da abertura de um processo independentista, em relação à América portuguesa, mostrava ser viável.

No universo político luso-americano, os anos entre 1808 e 1822 foram, portanto, de emergência, coexistência e conflito entre diferentes alternativas pensadas em resposta a uma grave crise cada vez mais sentida pelos homens que a viviam; alternativas dentre as quais despontava a de ruptura entre Portugal e Brasil e a de configuração deste como um corpo político autônomo (a exemplo do que pouco antes ocorrera com a quase totalidade da América espanhola). Nesse sentido, a independência do Brasil foi condicionada historicamente pela "experiência hispano-americana".

Uma das dimensões menos conhecidas da trajetória das Américas portuguesa e espanhola, ao mesmo tempo distinta e comum, diacrônica e sincrônica, é, conforme indicamos acima, o da presença, nos espaços públicos de discussão política luso-americanos, de escritos de caráter doutrinário e programático que, tendo por base o que ocorria na América espanhola, para além de informações, traziam análises e prognósticos acerca dos destinos do Novo Mundo. A circulação desses escritos, por seu turno, precipitava debates e incentivava novos prognósticos específicos a respeito da América portuguesa.

Editado mensalmente em Londres a partir de junho de 1808, o Correio Brasiliense logo se constituiu num dos repositórios mais importantes a disponibilizar, aos portugueses da época, informações do que ocorria na Espanha e suas Américas. Dirigindo críticas ao governo luso numa perspectiva reformista monárquica, era formalmente proibido em Portugal e no Brasil, onde não apenas circulava em profusão como era lido até mesmo pela Corte do Rio de Janeiro. Ao longo de seus vinte e nove volumes, encerrados em dezembro de 1822, o Correio Brasiliense publicou regularmente boatos, notícias, documentos e análises sobre acontecimentos mundiais, especialmente os ligados aos mundos português e espanhol. E em uma seção específica, "Literatura e Ciências", noticiava e resenhava obras que considerava de interesse a seus leitores. ${ }^{10}$

Em cinco números editados entre 1808 e 1810, o Correio Brasiliense transcreveu trechos e comentou análises, realizadas pela influente revista literária trimestral Edinburgh Review, de três obras sobre a América espanhola: a Carta derijida a los Españoles Americanos, por uno de sus compatriotas, de Juan Pablo Viscardo y Guzmán; ${ }^{11}$ o Compendio de la Historia Geográfica, natural e civil de Chile, de Ignácio Molina;12 e o Ensayo politico sobre el reino de la Nueva-España, de Alexandre Humboldt. ${ }^{13}$ Todas elas ofereceram pretextos para a Edinburgh Review e o Correio Brasiliense traçarem conjecturas sobre a independência da América espanhola e, no caso deste último, também do Brasil.

$\mathrm{Na}$ Edinburgh Review, a Carta derijida a los Españoles Americanos é ponto de partida para uma reflexão acerca dos interesses britânicos na independência da América espanhola. Perseguida anteriormente pelas gestões de Francisco de Miranda junto ao gabinete britânico em 1790, e atualmente por Napoleão Bonaparte como meio de enfraquecer a Espanha, a independência da América seria, para a Edinburgh Review, 
Citada no Correio Brasiliense v.ll, n.13, 06/1809. Desde meados do século XVIII interesses ligados à economia britânica viam positivamente a perspectiva de que, um dia, os mercados coloniais americanos, sujeitos ao monopólio, lhe fossem franqueados. STREET, John. Gran Bretaña y la independencia del Rio de la Plata. Buenos Aires: Paidós, 1967. esp. p.19-27.

15

Correio Brasiliense v.II, n.11, 04/1809.

16

Citada pelo Correio Brasiliense v.III, n.16, 09/1809.

17

Correio Brasiliense v.IV, n.25, 06/1810. inevitável, devendo se suceder mais dia menos dia sem que, no entanto, ela devesse ser incentivada pela Grã-Bretanha por conta de suas boas relações com a Espanha. ${ }^{14}$ Já para o Correio Brasiliense, a Carta derijida tinha em vista
a separação das colônias Européias na América; acontecimento, que todos os politicos têm previsto há muitos anos, e que se tem já começado a pôr em prática, primeiro nos Estados Unidos, e depois no Brasil. A separação destas duas diferentes porções de colônias de suas metrópoles européias, teve motivos e causas, na aparência, muito diversas, mas na realidade foram as mesmas; porque a independência dos habitantes do Mundo é conseqüência necessária da sua situação local, e a causa próxima, que a acelera ou desenvolve, é coisa meramente acidental. ${ }^{15}$

A Historia de Ignácio Molina incentiva a Edinburgh Review a traçar um quadro mais detalhado de expectativas em torno da independência da América espanhola, reforçada como inevitável, já que "uma variedade de causas tem contribuido a enfraquecer a cadeia que atava estas colônias à sua metrópole; cadeia que agora se pode supor quebrada, e impossivel o reuni-la outra vez". Assim, conjecturava:

\begin{abstract}
se a Espanha ficar independente [da França], a América do Sul pode 10 ficar unida com ela no estado de vassalagem, em que até aqui tem estado; 20 pode ficar unida com ela em sua livre associação, ou união, como a da Irlanda com a Grã-Bretanha; 30 pode revoltar-se dela com o adjutório de Bonaparte; 40 pode revoltar-se com a assistência da Grã-Bretanha; 50 pode se revoltar dela sem assistência de ninguém". [No entanto, continuava], "se a Espanha ficar sujeita a Bonaparte, a América Meridional pode 10 ficar unida com a Espanha em estado de vassalagem, mas não em associação livre; porque com uma coroa despótica, não pode haver união de súditos de outra maneira que não seja vassalagem; $2 \underline{0}$ a América Meridional pode reivindicar a sua independência com o adjutório da Grã-Bretanha; 3 o pode fazê-lo sem adjutório de ninguém. ${ }^{16}$
\end{abstract}

Quando a obra em questão é o Ensayo politico de Humboldt e o espaço de observação incide sobre a Nova Espanha, a Edinburgh Review parece recuar, diagnosticando a ausência de um sentimento, na América, favorável ao rompimento com a Espanha. No entanto, o Correio Brasiliense, que na mesma edição em que trouxe a resenha da resenha da obra de Humboldt publicou também a primeira notícia a respeito da formação da junta de governo de Caracas em 19 de abril de 1810, tinha fortes elementos para discordar, pois "a recente revolução de Caracas, em que este país se declarou independente [...] mostra bem quanto os Revisores [da Edinburgh Review] se enganaram no caráter que deram a estas comoções da América Espanhola"17.

A complexidade que o desenvolvimento histórico das relações entre Espanha e América carrega a partir de 1810, colocando lado a lado uma variedade de projetos e alternativas que de início não apresentam, de fato, qualquer sinal seguro de que prevaleceria o rompimento entre colônias e metrópole, não impede a presença, nesse cenário, de um dado concreto: a independência das colônias era aventada, menos por aqueles que acabariam por concretizá-la, e mais por aqueles que observavam a história do tempo presente. Desde 1808, as expectativas nessa direção eram fortes, integrando espaços públicos de discussão política e se convertendo, assim, num dado daquela realidade, mesmo que isso não assegurasse seu triunfo. 
18

Examen imparcial de las disensiones de la América con la España; de los medios de su reciproco interés, y de la utilidad de los aliados de la España. Por D. Alvaro Flores Estrada, procurador geral de Astúrias. Londres, 1811. Resenhado no Correio Brasiliense v.VII, 07/1811, e 08/1811.
19

ESTRADA, Álvaro Flores. Op.Cit. Citado pelo Correio Brasiliense v.VII, 07/1811.

20

Correio Brasiliense v.VII, 08/1811.

21

Historia de la Revolución de Nueva España, antiguamente Analmac; ou verdadeira origem e causas dela, com a relação de seus progressos, até o presente ano de 1813. Por D. José Guerra, da Universidade do México. Resenha no Correio Brasiliense v.XI, 11/1813.
Denunciando essa complexidade, vários observadores coevos mostram uma clara dificuldade em aceitar a idéia de inevitabilidade da independência da América espanhola, mesmo que a tenham esboçado anteriormente. 0 espanhol peninsular Álvaro Flores Estrada, num Examen imparcial de las disensiones de la América con la España; de los medios de su reciproco interés, y de la utilidad de los aliados de la España, resenhado pelo Correio Brasiliense, abordava, dentre outras questões, o fato da Junta Central de Sevilha não ter concedido, quando de sua convocação aos representantes da nação espanhola, uma distribuição igualitária entre deputados da Espanha e das Américas. ${ }^{18}$ Com isso,

em vez de estreitar os vínculos das Américas com a Peninsula, autorizando-as para nomear e formar Juntas Provinciais, compostas de individuos elegidos por todos os naturais daqueles domínios, que era o único meio de cortar pela raiz as repetidas injustiças cometidas naqueles paises pelas autoridades nomeadas pelo Governo, tratou [a Junta] de abolir as da Península, e não cuidou em estabelecer as da América. Seguramente esta única providência teria enchido de gozo a todos os Americanos, e teria impedido deste modo que se tivesse formado nenhum partido de descontentes.

Para Flores Estrada, o princípio de que "todos os homens, todos os paises, tendo um direito imprescritivel de procurar a sua felicidade, o tem também de remediar os seus males, reformar os seus abusos, e melhorar as suas instituições" explicaria a formação de juntas não apenas em Caracas, mas também em Buenos Aires, resultado de justos descontentamentos para com uma má gestão metropolitana; mesmo assim, nada atribuiria à América o pleno direito de romper com a Espanha e com uma união sustentada em princípios e costumes considerados legítimos. ${ }^{19}$ Já para o Correio Brasiliense, a leitura da obra de Flores Estrada mostraria que, embora o momento não fosse propício, este rompimento deveria se consumar em breve. 20

Há que se lembrar que o Correio Brasiliense não apenas era editado em Londres, mas também incorporava ao seu projeto reformista monárquico, de defesa da manutenção da unidade portuguesa com base em transformações no tocante à sua gestão política, uma série de tópicos de um ideário livre-cambista que, à época, tinha na política externa britânica o seu grande baluarte mundial. Com isso, alinhava-se a vários observadores britânicos - como, por exemplo, os redatores da Edinburgh Review - que não apenas aventavam, mas até mesmo desejavam que a América se tornasse independente da Espanha, sendo a idéia de sua "inevitabilidade" uma das mais fortes expressões desse pensamento. Para o Correio, a leitura de uma outra obra, a Historia de la Revolución de Nueva España ${ }^{21}$ de José Guerra, escrita em resposta à Origen de la espantosa Revolución de Nueva España de Juan Lopes Cancelada, mostraria "à Espanha Européia, que deveria ter olhado para a América com olhos muito mais sérios do que até aqui tem feito; e que o não terem conhecido na Europa o que é a América, Ihes tem custado muito caro". Pouco adiante, retomando uma imagem que se fazia cada vez mais presente no universo discursivo da política da época, o Correio afirmava que

mais de uma vez temos comparado as potências Européias, em sua política para com as colônias, com um homem que trata de criança seu filho adulto; e a este errado sentimento temos atribuido a adoção de muitas medidas que desaprovamos. É absolutamente essencial que o pai de família mude e altere o 
22

Correio Brasiliense v.XI, 11/1813.

23

Dominique-Georges-Frédéric de Riom de Prolhiac de Fourt de Pradt (1759-1837), fora arcebispo de Malines e deputado do clero da Normandia nos Estados Gerais franceses. Quando da Revolução de 1789, De Pradt converteu-se numa liderança contra-revolucionária e monarquista, mas logo ocuparia importantes postos na ordem napoleônica, sendo designado embaixador da França em Varsóvia. Em 1801-1802 publicou em Paris sua primeira obra de grande impacto : Les trois âges des colonies, ou de leur état passe, présent et à devenir. Em seguida, numerosos escritos que foram traduzidos, comentados e publicados em várias línguas, muitos deles relativos à América, como: Du Congrès de Vienne (Paris, 1815-1816); Mémoires historiques de la Révolution de l'Espagne (Paris, 1816) ; Des colonies et de la revolutión actuelle de l'Amérique (Paris, 1817) ; Des trois derniers mois de l'Amérique et du Brésil (Paris, 1817); Pièces reatives á Saint Domingue et á l'Amérique (Paris, 1818) ; De la révoIution actuelle de l'Espagne et de ses suites (Paris, 1820); L'Europe et l'Amérique depuis le Congrès de Aix-la-Chapelle (Paris, 1821); L'Europe et I'Amérique en 1821 (Paris, 1822); Examen du plan aux Cortes sur la reconnaissance de l'independénce de l'Amérique espagnole (Paris, 1822) ; L'Europe et l'Amérique en 1822 et 23 (Paris, 1824-1828); Vrai système de l'Europe relativement à l'Amérique et à la Grèce (Paris, 1825); Congrès de Panamá (Paris, 1825) ; e Concordat de l'Amérique avec Rome (Paris, 1827). Para uma lista completa de suas obras, edições e traduções entre 1790 e 1837, vide AGUIRRE ELORRIAGA, Manuel. El abate De Pradt en la emancipación hispanoamericana (1800-1830). Caracas: Universidad Católica Andrés Bello, 1983. p.303-306.

24

MOREL, Marco. Independência no papel: a imprensa periódica. In: JANCSÓ, István (org.). Independência: história e historiografia. São Paulo: Hucitec, 2005. p.620-630; ARAÚJ0, Ana Cristina. Um império, um reino e uma monarquia na América: as vésperas da independência do Brasil. In: JANCSÓ, István (org.). Op.Cit. p.263-264.

25

DE PRADT. Des trois derniers mois de l'Amerique meridional et du Brésil, 1817. Utilizei a tradução para o português do Correio Brasiliense, que resenhou a parte da obra referente ao Brasil em seu v.XIX, 09/1817. modo de proceder para com seus filhos, à proporção que eles se adiantam em idade; e pelo mesmo princípio a política que as nações Européias tinham adotado há 300 anos, quando as suas colônias estavam em absoluto estado de infância, é evidentemente inaplicável quando essas colônias tem chegado a um estado de população, riquezas e influência, que naturalmente lhe dão preponderância entre as nações. 22

Possibilidade, inevitabilidade e desejo de independência da América compunham um mesmo espectro multifacetado de idéias, discursos e práticas, que se plasmavam no conceito de emancipação. No mundo luso-americano, a equação entre estes termos se redefine no momento em que fica claro que as desventuras pelas quais passava a América espanhola - conflitos de posições, guerras civis e uma profunda instabilidade - se faziam presentes também no mundo português. Em 1817, dois projetos contestatórios distintos e igualmente sérios vieram à tona na América portuguesa - a revolução republicana na capitania de Pernambuco e adjacências - e em Portugal peninsular - a conspiração liderada por Gomes Freire de Andrade, logo após a Corte do Rio de Janeiro materializar a dimensão agressiva de sua política externa americana com a ocupação de Montevidéu. No mesmo ano, vinham à luz, em Paris, duas obras do já célebre abade De Pradt, que há algum tempo vinha prognosticando não apenas a independência da América espanhola, mas na sua esteira, também a da América portuguesa: Des colonies et de la revolutión actuelle de I"Amérique e Des trois derniers móis de I"Amérique et du Brésil.23 Inteirando-se dos acontecimentos de seu tempo, acompanhando-os e analisando-os, De Pradt atualizava suas idéias centrais em uma larga e dinâmica produção editorial. Seus prognósticos se fizeram intensamente presentes nos espaços públicos de discussão política luso-americanos, ${ }^{24}$ e seu nome cada vez mais uma referência positiva para aqueles que começavam a acreditar não apenas na possibilidade, mas também na inevitabilidade e benignidade da separação de destinos entre Portugal e Brasil.

Para De Pradt, com a transferência da Corte portuguesa em 1808,

\begin{abstract}
tudo se mudou em Portugal, no Brasil, e talvez no mundo. 0 navio, que levou El Rei de Portugal, levou consigo novos destinos para o universo. Apenas se percebeu a natureza de tão importante acontecimento. Era necessário tudo quanto se tinha passado, para atrair a isto atenção. Pela mudança da residência d'El Rei se inverteu toda a antiga ordem entre Portugal e o Brasil, e entre Brasil e Portugal. Um tomou o lugar do outro [...]. Formaram-se imediatamente duas novas combinações entre Portugal, reduzido agora a colônia, e o Brasil vindo a ser metrópole; entre o Brasil aspirando a conservar o Rei, e Portugal de sua parte aspirando a recuperá-Io; entre o Brasil vivificado e enriquecido pela presença do Soberano, e Portugal humilhado e empobrecido pela sua ausência, e afligido pela distância.
\end{abstract}

E assim, sentenciava, "El Rei não pode conservar o seu domínio em Portugal e no Brasil; e deve escolher ou ser Rei de Portugal e abandonar o Brasil, ou ser Rei do Brasil e abandonar Portugal".25

Em 1817, a questão da permanência ou não de D. João e sua Corte no Rio de Janeiro mesmo após o término da guerra peninsular e a restauração legitimista da Europa, dividia opiniões no interior do mundo português, e gerava um debate que, pelos quatro anos subseqüentes, se faria cada vez mais influente nos destinos de Portugal e Brasil. Para De 
Pradt, a solução para a questão deveria ser concebida a partir de um pressuposto: a separação entre Portugal e Brasil era inevitável. Por isso, opinava que D. João deveria

\section{6}

DE PRADT. Des trois derniers mois de l'Amerique meridional et du Brésil, 1817. Correio Brasiliense, v.XIX, 09/1817.

\section{7}

DE PRADT. Des colonies et de la revolutión actuelle de I"Amérique, 1817. Citado por MOREL, Marco. Independência no papel: a imprensa periódica. In: JANCSÓ, István (org.). Independência: história e historiografia. São Paulo: Hucitec, 2005. p.622.

\section{8}

A idéia era amplamente difundida. Em 1816, o inglês Henry Koster, tendo vivido na capitania de Pernambuco no inicio do século XIX, pôde escrever do Brasil, em 1816, que "a vinda do Soberano para este pais animou bastante pessoas que, há tempos, estavam com os hábitos de indolência e desenvolveu a atividade de outros que esperavam o momento de despertar [...]. Este rebento do nosso continente europeu crescerá e a árvore que produzir será mais poderosa que o ramo de onde nasceu". Citado por BERNARDES, Denis de Mendonça. Pernambuco e sua área de influência: um território em transformação (1780-1824). In: JANCSÓ, I. (org.). Op.Cit. p.388-389. Para outros testemunhos e análises de idêntico teor, vide KRAAY, Hendrik. A visão estrangeira: a independência do Brasil (1780-1850) na historiografia européia e norte-americana. In: JANCSO (org.). Op.Cit. p.128.

\section{9}

Para as divergências do Correio Brasiliense para com De Pradt, vide MOREL, Marco. Independência no papel: a imprensa periódica. In: JANCSÓ, István (org.). Op.Cit. p.624-628. A idéia de "emancipação" das colônias européias do Novo Mundo não era estranha ao editor do Correio Brasiliense, tampouco incompativel com pressupostos do reformismo ilustrado luso-americano das primeiras décadas do século XIX. 0 problema seria associar inevitabilidade com desejo de ruptura, bem como conferir a esta um caráter de enfrentamento entre Brasil e Portugal que não pautou, via de regra a consecução do projeto de independência brasileiro em 1822. José Bonifácio de Andrada e Silva, por exemplo, leu e anotou pelo menos duas obras de De Pradt relativas ao Brasil: Des colonies et de la revolutión actuelle de l"Amérique e Des trois derniers mois de l'Amerique meridional et du Brésil, ambas de 1817. Em seus escritos políticos, a idéia de um futuro onde Brasil e Portugal estariam separados seria, como é sabido, uma presença constante (para uma análise das leituras de Bonifácio da obras de De Pradt: SILVA, Ana Rosa C da. Construção da nação e escravidão no pensamento de José Bonifácio, 1783-1823. Campinas: Editora da Unicamp, 1999. p.100-104; e ARAÚJO, Valdei Lopes de. A experiência do tempo. Modernidade e historicização no Império do Brasil, 1813-1845. Tese (doutorado em História Social da Cultura). Pontificia Universidade Católica do Rio de Janeiro, Rio de Janeiro, 2003. p.85 e segs.

\section{0}

Paris, 1820. Transcrita no Correio Brasiliense v.XXIV 02/1820. Utilizo a tradução para o português do Correio.

31 Ibidem. fazer-se plenamente Brasiliano; deixar de olhar da América para Portugal com olhos saudosos, ou de avançar e retrogradar para o caminho antigo. [...] Em vez de se entreter com lamentar a perda de um estreito território, como é Portugal, uma alma elevada daria graças ao Céu pela necessidade que o levou a um país de extensão ilimitada, e de riquezas imensas; e pelos novos destinos que a Revolução Americana está preparando ao mundo. ${ }^{26}$

A independência do Brasil era inevitável, ademais, porque fazia parte de um movimento irreversivel, precipitado recentemente pela América espanhola. ${ }^{27}$ No entanto, a despeito do que pensava e escrevia De Pradt, e do que se tornava a expectativa preponderante a respeito da América espanhola nos espaços públicos de discussão política luso-americanos, em 1817 a pluralidade conflitiva de projetos e alternativas de futuro ainda era a característica mais marcante do panorama político iberoamericano.

o Correio Brasiliense traduzia, transcrevia e comentava longas passagens das obras de De Pradt, discordando do autor francês em pontos sensiveis. É o caso da idéia de que, com os acontecimentos de 1808, a separação entre Portugal e Brasil começara a se delinear, permitindo, da parte de De Pradt, a concepção do processo aí supostamente desencadeado em termos de "emancipação".28 Para o editor do Correio, imbuído de principios claramente monarquistas reformistas, o fato da América ter se tornado sede da monarquia portuguesa não implicaria, necessariamente, fissuras irremediáveis nas relações entre as partes que tradicionalmente a compunham. Pelo menos, desde que o governo português estivesse atento à necessidade de reformas no império. ${ }^{29}$ De outra parte, a independência da América espanhola, que no final da década de 1810 já caminhava de maneira decidida rumo à sua consecução, não se completara: México, América Central, Cuba e Porto Rico mantinham-se monárquicos, bem como partes da Venezuela, Peru e Alto Peru. Por isso, as incertezas predominavam, parecendo plausivel até mesmo uma restauração realista naquela que era, sem dúvida, a região onde tal possibilidade se encontrava mais remota: as províncias do Rio da Prata.

0 Correio Brasiliense transcreveu, em fevereiro de 1820, uma publicação intitulada As províncias de La Plata, erigidas em Monarquia. Considerações políticas pelo C. de S.30. "Na situação em que se acham hoje em dia as Cortes de Madri, do Rio de Janeiro e o Governo de Buenos Aires", propunha seu autor, "o único meio de restabelecer entre as três potências uma paz durável, é reunir as províncias de La Plata em monarquia, e de lhe dar para rei o Infante D. Sebastião de BourbonBragança [...]. Este projeto, longe de experimentar dificuldades da parte do Governo de Buenos Aires, é inteiramente conforme a suas vistas; tem por muitas vezes feito esta proposição ao Rei de Portugal". Isto porque

os homens que tem mais influência na administração desta República, instruídos pela experiência, pelo exemplo das revoluções Européias, e pela natureza do Governo Republicano, estão intimamente convencidos de que somente uma constituição monárquica pode garantir a tranqüilidade exterior e interior de um grande Estado, consolidar todos os direitos, e firmar as instituições sobre que descansa a liberdade política. ${ }^{31}$ 
32

GOLDMAN, Noemi (dir.). Nueva historia Argentina, tomo III: revolución, república, confederación. Buenos Aires: Sudamericana, 1998; CHIARAMONTE, José Carlos. Ciudades, provincias, Estados: Origenes de la nación Argentina (1800-1846). Buenos Aires: Ariel, 1997.

33

Utilizei a edição española, De la revolución actual de la España y de sus consecuencias. Valencia: 1820. p.114.

\section{4}

DE PRADT. De la revolución actual de la España y de sus consecuencias. Valencia: 1820. p.177-178.

\section{5}

Ibidem. p.178-179.

36

Ibidem. p.183. Grifos do autor.

37

Dentre outros: ALEXANDRE, Valentim. Os sentidos do império: questão nacional e questão colonial na crise do Antigo Regime português. Porto: Afrontamento, 1993; BERBEL, Márcia. A nação como artefato: deputados do Brasil nas Cortes portuguesas, 1821-1822. São Paulo: Hucitec, 1998; JANCSÓ, István; PIMENTA, João Paulo G. Peças de um mosaico (ou apontamentos para o estudo da emergência da identidade nacional brasileira). In: MOTA, Carlos G. (org.). Viagem incompleta: a experiência brasileira 1500-2000. São Paulo, Senac, 2000.
A existência de tal projeto nos primeiros meses de 1820 deve ser entendida numa tripla perspectiva. Em primeiro lugar, pelo colapso do centralismo político sediado em Buenos Aires a partir da rejeição da Constituição das "Províncias Unidas do Rio da Prata" pela maioria das províncias que deveriam integrá-la; e se em 1820 a restauração do tradicional realismo bourbônico era impossivel na região, a inexistência de qualquer unidade política estável e abrangente abria o flanco para novas alternativas. 32 Em segundo lugar, como ecos duradouros de projetos de monarquia de vária natureza que vinham sendo aventados na região desde 1810. E finalmente, como uma percepção não apenas de que a presença de um grande bastião legitimista no continente americano, como o Brasil, poderia influir decisivamente na existência futura dos espaços políticos hispano-americanos, mas também de que a sorte desses espaços não poderia ser indiferente ao Brasil. Essa reciprocidade de influências era, à época, amplamente reconhecida por estadistas, periodistas e praticamente todos os demais sujeitos atuantes no universo político lusoamericano.

Porém, convém destacar que o autor de As províncias de La Plata, erigidas em Monarquia não teve conhecimento dos acontecimentos da Espanha dos primeiros dias do ano de 1820, e que sepultariam a possibilidade de consecução de projetos como esse. 0 segundo movimento constitucionalista espanhol, iniciado junto às tropas que se preparavam, na ilha de León, para uma expedição militar de reconquista da América, abriu um novo horizonte de reflexões e prognósticos acerca do futuro do continente americano, reforçando posições como as de De Pradt, que atrelavam as independências das colônias portuguesas e espanholas.

Em De la révolution actuelle de l'Espagne et de ses suites, De Pradt afirmava ser evidente, em 1820, que "una nueva conquista de la América era un delírio".33 A partir dessa constatação e retomando opiniões anteriormente expressas em Des trois derniers, prognosticava os efeitos do levante de León sobre Portugal e América: "Su rei [de Portugal] está ausente y para siempre; ha dejado de ser portugues para hacerse brasileño; el camino para volver á Europa le está cerrado, y no se le abrirá sino á costa de perder el Brasil".34 Por isso, continuava, "como no hay causa alguna poderosa que no produzca un pronto efecto", seria natural esperar que "el acontecimiento de la España afectando con eficacia los ánimos en Portugal, le conducirá muy pronto á poner fin á la situación problemática é insoportable en que se halla, y por consecuencia á buscar un rey que resida en su país independiente del Brasil, dejando a este independiente del Portugal, y á colocar este trono al nivel de los tronos constitucionales que se erigen en la Europa". ${ }^{35} \mathrm{E}$ com isso o Brasil seguiria o mesmo curso do "imenso continente de la América meridional", que "debia considerarse positivamente y de hecho en plena y absoluta independencia". 36

Como sabemos, os prognósticos do abade não estavam muito longe da realidade, e de fato, poucos meses depois, em agosto de 1820, também em Portugal eclodiu um movimento constitucionalista, cuja contribuição para uma acelerada definição de incompatibilidades no seio da nação portuguesa e para a emergência de um projeto político de independência do Brasil tem sido cada vez mais esquadrinhada pela historiografia recente. ${ }^{37}$ Por ora, o que importa é salientar que, quando isso ocorre, ou 
Pelo menos à medida que o Revérbero tornavase destacado porta-voz do projeto de ruptura política entre Brasil e Portugal. MOREL, Marco. Independência no papel: a imprensa periódica. In: JANCSÓ, István (org.). Independência: história e historiografia. São Paulo: Hucitec, 2005. p.629. Sobre as mudanças na posição de seus editores ao longo dos anos de 1821 e 1822, vide: OLIVEIRA, Cecilia de S. A astúcia liberal: relações de mercado e projetos políticos no Rio de Janeiro (1820-1824). Bragança Paulista: EDUSF, 1999.

\section{9}

Revérbero Constitucional Fluminense $n .17$, 17/09/1822; n.18, 24/09/1822; n.19/01/10/1822; e n.20, 08/10/1822. Em Cuba, o Infante tomou parte na fracassada conspiração liderada em 1811 por Román de la Luz Sánchez Silveira; sendo o único a escapar da pena capital, pôde ver um projeto de Constituição para a ilha, de sua autoria, publicado na Venezuela em 1812. Cinco anos depois, participou da igualmente fracassada expedição de libertação de Nova Espanha organizada por Francisco Javier Mina, e existem indícios de que antes de se exilar na Espanha, esteve também na província luso-americana de Pernambuco, quando esta se encontrava convulsionada pela revolução de 1817. A Solución a la cuestión de derecho sobre la emancipación de la América, por el ciudadano Joaquín Infante, natural de la isla de Cuba foi publicada em Cádiz, em 1821. Desenvolvi com mais detalhamento a análise da transcrição e comentário da obra de Infante pelo Revérbero em: PIMENTA, João Paulo G. La independencia de Hispanoamérica en la prensa de Brasil: paralelismos, pronósticos y articulaciones políticas, 1820-1822. In: FRASQUET, Ivana (coord.). Bastillas, cetros y blasones. La independencia en Iberoamérica. Madrid: Fundación Mapfre, 2006. p.285-297. 0 texto integral da Solución a la cuestión de derecho sobre la emancipación de la América, por el ciudadano Joaquín Infante, natural de la isla de Cuba encontra-se publicado por MORALES BECERRA, Alejandro (comp.). México, una forma republicana de gobierno, t.l: la forma de gobierno en los congresos constituyentes de México. México: Instituto de Investigaciones Juridicas de la UNAM, 1995 (www. bibliojuridica.org/libros/libro.htm?|=595).

\section{0}

Revérbero Constitucional Fluminense n.17,

17/09/1822. No original de Infante: "la naturaleza ha constituido las naciones, trazándoles un círculo en que se estrechen, y separándolas por barreras, cuya violación es siempre funesta [...].. Así vemos en la Europa, por ejemplo, la diferencia de España a Francia por los Pirineos, la de esta a Italia por los Alpes, la de Inglaterra a las naciones septentrionales del continente por el mar que la aisla, \&tc. Contrayendo esta evidencia al nuevo mundo respecto al viejo, ¿puede haber un límite más marcado que el de la duplicidad de continentes? Y respecto a la España, ¿puede haber mayor separación que la de un mar de mil y quinientas leguas por la parte más cerca, que es el golfo mexicano? Es, pues, claro que la sujeción de unos pueblos a otros en tal caso es violenta y precaria y que al fin la demarcación política ha de arreglarse a la demarcación fisica". MORALES BECERRA, Alejandro (comp.). Op.Cit. p.207 (www.bibliojuridica.org/libros/ libro.htm?|=595).

41

Revérbero Constitucional Fluminense n.17, 17/09/1822. Para um desenvolvimento da idéia de seja, ao longo dos anos de 1821 e 1822, os espaços públicos de discussão política luso-americanos já dispunham de uma considerável reflexão em torno da possibilidade dessa independência que, conforme vimos, vinha sendo aventada de diferentes formas por diferentes interlocutores. Uma reflexão que se reconfigura, mais uma vez, de acordo com os ritmos da própria realidade histórica sobre a qual incide.

Em 1821 a América espanhola apresentava um aspecto geral de ruptura quase que total em relação à Espanha (as exceções eram Cuba, Porto Rico e Alto Peru). Esse quadro era de amplo conhecimento no mundo português, informado, documentado e analisado à exaustão por um conjunto de periódicos que, por conta da regulamentação para o Brasil dos decretos lisboetas de liberdade de imprensa, não paravam de crescer. Um deles, o Revérbero Constitucional Fluminense, além de logo se converter em um dos mais aguerridos defensores do projeto de independência do Brasil, era também um dos que mais recorria aos "ensinamentos" da América espanhola e à autoridade do abade De Pradt. ${ }^{38}$ E numa das ocasiões em que o fez, justamente durante as semanas nas quais se formalizava a ruptura entre Brasil e Portugal, o Revérbero criou um documento formidável.

Trata-se da transcrição parcial e comentada da Solución a la cuestión de derecho sobre la emancipación de la América, por el ciudadano Joaquin Infante, natural de la isla de Cuba. ${ }^{39}$ Em linhas gerais, a Solución de Infante defendia a legitimidade e a inevitabilidade da independência (isto é, da emancipação) de toda a América espanhola. Dividida em "razones filosóficas" e "razones políticas", traz vários argumentos nesse sentido, cada qual encontrando, na publicação do Revérbero, notas de rodapé com aproximações entre as realidades hispano e lusoamericana e defesas da validade dos argumentos de Infante também para o Brasil. Tomemos, a título de exemplo, dois argumentos bastante comuns à época. Em primeiro lugar, o de que o continente americano estaria destinado a ser "livre" da Europa por uma atribuição da própria natureza, que o fez distinto e afastado do Velho Mundo. Para Infante,

a Natureza constituiu as Nações, traçando-Ihes um círculo em que se encerrem, e separando-as por barreiras, cuja violação é sempre funesta [...]. Assim vemos na Europa, por exemplo, a diferença da Espanha à França pelos Pirineus; desta com a Itália pelos Alpes; a Inglaterra com as Nações setentrionais pelo mar que as separa. Aplicando esta evidência ao Novo Mundo, relativamente ao Velho, pode haver um limite mais assinalado, que o da duplicidade de dois Hemisférios? E quanto à Espanha, pode haver maior separação que a de um mar de 1500 léguas na parte mais contígua, que é o Golfo do México? É portanto claro, é evidente, que a sujeição de uns a outros é em tal caso violenta, e precária, e que enfim a demarcação política há de regular-se pela demarcação física 40 .

Na mesma linha, agrega o Revérbero:

não sei como podem os emperrados [das Cortes] persistir na louca pretensão de domínio, e direito de Portugal sobre o Brasil. As razões desenvolvidas neste excelente Capítulo são para a América Espanhola, como para o Brasil"; afinal, "a Emancipação das Colônias está baseada na Natureza, é uma progressão do desenvolvimento das suas forças. ${ }^{41}$

Em segundo lugar, a questão da definitiva separação de destinos promovida por metrópoles que buscariam, por meio da força, uma 
"identidade territorial" do Brasil no contexto da crise do Antigo Regime português na América, vide: PIMENTA, João Paulo G. Estado e nação no fim dos impérios ibéricos no Prata (1808-1828). São Paulo: Hucitec/Fapesp, 2002.

\section{2}

Revérbero Constitucional Fluminense n.20, 08/10/1822. No original de Infante: "La España misma se arruinará al cabo inútilmente con semejante empeño; bastando para convencerse de esta verdad el dato reciente de la Francia con la parte de la isla de Santo Domingo que fue suya, y ha tenido que ceder a la gente de color que la defendia, después de perder cien mil hombres más o menos, y de gastar inmensas sumas, entablando al fin más cuerdamente con aquellos habitantes relaciones mercantiles, útiles a uno y a otro pueblo" (MORALES BECERRA, Alejandro (comp.). México, una forma republicana de gobierno, t.I: la forma de gobierno en los congresos constituyentes de México. México: Instituto de Investigaciones Jurídicas de la UNAM, 1995. p.212 (www.bibliojuridica.org/libros/libro. htm?|=595).

\section{3}

Revérbero Constitucional Fluminense n.20, 08/10/1822.

\section{4}

Revérbero Constitucional Fluminense n.20, 08/10/1822. No original de Infante: "Faltando, pues, la confianza mutua, y siendo implacable hoy el odio de españoles y americanos, se ha roto para siempre el lazo que unía las colonias a la metrópoli, y no queda otro arbitrio para reconciliación tan suspirada que la emancipación. No era la fuerza, sino la opinión y buena armonía, lo que sujetaba las colonias a la metrópoli. Cambió la opinión y desapareció el acuerdo: la separación quedó hecha" (MORALES BECERRA, Alejandro (comp.). Op.Cit. p.212 (www.bibliojuridica.org/libros/libro. htm?|=595).

\section{5}

Revérbero Constitucional Fluminense n.20, 08/10/1822. restauração da unidade entre Europa e América supostamente perdida. Segundo Infante,

a Espanha por fim se arruinará inutilmente com semelhante empenho de reconquistar a América, bastante para convencer-se desta verdade o caso recente da França com a parte da Ilha de São Domingos, que foi sua, e teve de ceder à gente de cor que a defendia depois de perder cem mil homens pouco mais ou menos, e gastar imensas somas estabelecendo por fim com aqueles habitantes, relações mercantis úteis a ambos os povos. ${ }^{42}$

A este propósito, o Revérbero se pergunta:

não tomará Portugal esta doutrina? De nada Ihe servirão as lições da História? De nada a experiência dos males alheios? Aparentando uma ignorância que não tem das coisas, e da opinião do Brasil, fazem os últimos esforços para nos enviarem tropas, e reduzir-nos como já dizem seus Deputados à escravidão?. ${ }^{43}$

De novo Infante:

faltando, pois, a mútua confiança, e sendo hoje implacável o ódio dos Espanhóis e Americanos, rompeu-se para sempre o laço que unia as Colônias à Metrópole, e não resta outro arbitrio para a reconciliação tão suspirada, senão a emancipação. Não à força, sim à opinião e à boa harmonia é que sujeitavam as Colônias à Metrópole. Mudou-se a opinião: desapareceu a harmonia, fez-se a separação. ${ }^{44}$

Por fim, o Revérbero:

também entre o Brasil e Portugal está feita a separação. A Independência do Brasil é um desses acontecimentos necessários, que nenhuma força humana pode obstar. 45

Ademais de denunciar, de modo cristalino, a conversão da idéia de possibilidade da independência da América espanhola em sua inevitabilidade e positividade (tomando-a, portanto, como emancipação), a publicação, pelo Revérbero, da Solución de Infante consagra a percepção, bastante recorrente à época, de que a América portuguesa se inseria numa mesma dinâmica histórica que os territórios à sua vizinhança. Por isso, não surpreende que o Revérbero insira, numa de suas notas ao texto de Infante, trechos de De Pradt, que não se mostrava indiferente ao fato do continente americano apresentar clara tendência de tornar seus tradicionais prognósticos realidade. Nela, bradava o abade:

a América arrancada à Europa, e entregue à América! Um mundo inteiro pertencendo finalmente a si mesmo! Todas as partes do Globo chamadas a lutar entre si com todas as faculdades do seu solo, e do seu clima; luta proibida até agora pelos interesses restritivos dos possuidores Europeus! Os Pavilhões da América flutuando livremente em todos os mares, correndo em alguns dias, ou em algumas semanas os espaços que os pavilhões Europeus não podem devassar senão em meses! Um comércio sem limite, sem termo possivel, aberto com paises cujo seio é prenhe de riquezas inexauriveis! Céus! Não parece que se completou neste momento a tua primeira criação! 46
Utilizo a tradução publicada no Revérbero Constitucional Fluminense (n.19, 01/10/1822), segundo o qual trata-se de uma obra de De Pradt chamada "Reconhecimento da independência das colônias da América pelos Estados Unidos". Não encontro referência a tal obra na listagem de AGUIRRE ELORRIAGA, Manuel. El abate De Pradt en la emancipación hispanoamericana (1800-1830). Caracas: Universidad Católica Andrés Bello, 1983. 
A publicação comentada da obra de Joaquín Infante, realizada pelo Revérbero Constitucional Fluminense, representa uma perfeita antologia do que se pretendeu mostrar até aqui. Uma apropriação de exemplos e lições oferecidas pela América espanhola à América portuguesa, na qual foram reconfiguradas e manejadas de acordo com interesses políticos específicos de grupos que se organizavam em torno de soluções para a crise do Império; o ritmo de desenvolvimento histórico da indissociação entre as trajetórias hispano e luso-americana que desembocam, ambas, nas Independências, mas obedecendo a uma pequena diferença temporal - antes a espanhola, logo a portuguesa - responsável pela configuração de uma sincronia diacrônica; a importância e a complexidade de espaços públicos de discussão responsáveis pela configuração de projetos e atuações políticas que definem as condições de possibilidade em meio

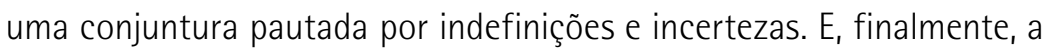
importância de uma dessas possibilidades - a independência da América portuguesa - que, se não estava assegurada em nenhum momento ao longo dos processos históricos que resultaram na sua concretização, era já um elemento presente e atuante numa realidade que, desde o século XVIII, começava a ser formada não apenas por práticas e idéias políticas, senão também por prognósticos. Pelo menos, desde o momento em que se tornara possivel alguém conceber, como Raynal, que o novo hemisfério deveria, um dia, desligar-se do velho. 